\title{
Unknown Supratentorial Localization
}

National Cancer Institute

\section{Source}

National Cancer Institute. Unknown Supratentorial Localization. NCI Thesaurus. Code C160161.

The supratentorial location is unknown. 